\title{
Evaluation of lightning current parameters using measured lightning induced voltage on distribution power lines
}

\begin{abstract}
In this paper, an algorithm had been proposed to evaluate the lightning current parameters using measured voltage from overhead distribution lines based on lightning location obtained from lightning location system. Moreover, the performance of algorithm had been considered using different samples of induced voltage. The results showed that the proposed algorithm could determine the lightning current parameters in an acceptable accuracy range. The proposed method is based on the measured values of lightning induced voltage as collecting this parameter is easier and more accessible than electromagnetic field components that had been widely used in past researches.
\end{abstract}

Keyword: Lightning; Lightning induced voltage; Channel base current 